\title{
Understanding the Mental Health Implications of Emotion Regulation: A Journey Through Authenticity
}

\section{Duygu Düzenlenmenin Psikolojik Sağlık Üzerindeki Etkilerini Anlamak: Özgünlüğün Aracı Rolü}

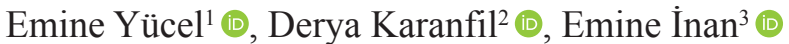

Research Assistant, Selcuk University, Faculty of Letters, Department of Psychology, Konya, Turkey

${ }^{2}$ Dr. Lecturer, İzmir Bakırçay University, Faculty of Arts and Sciences, Department of Psychology, Izmir, Turkey

${ }^{3}$ Dr. Lecturer, Ankara Yildirim Beyazit University, Faculty of Humanities and Social Sciences, Department of Psychology, Ankara, Turkey

ORCID: E.Y. 0000-0003-3663-6003;

D.K. 0000-0001-9358-6618,

E.I. $0000-0002-3531-4697$

\section{Corresponding author/Sorumlu yazar: \\ Emine Yücel, \\ Selcuk University, Faculty of Letters, Department of Psychology, Konya, Turkey E-mail/E-posta: ey.emineyucel@gmail.com}

Submitted/Başvuru: 12.06.2019 Revision Requested/Revizyon Talebi: 22.01.2020

Last Revision Received/Son Revizyon: 26.04.2020

Accepted/Kabul: 26.05.2020

Published Online/Online Yayın: 02.11.2020

Citation/Atıf: Yucel, E., Karanfil, D. \& Inan, E. (2020). Understanding the mental health implications of emotion regulation: $\mathrm{A}$ journey through authenticity. Psikoloji Çalışmaları - Studies in Psychology, 40(2): 477-512.

https://doi.org/10.26650/SP2019-0042

\begin{abstract}
People utilize specific emotion regulation (ER) strategies to exert control over their emotions. Some of those strategies are beneficial for psychological well-being, whereas others are detrimental to it. Identifying the working mechanisms of ER can be helpful to better understand its mental health implications. Particular ER strategies which interfere with one's natural emotional responses might lead people to conclude that they are not performing their authentic selves. However, other ER strategies can be useful in keeping one's authenticity intact. Given its importance for psychological well-being as well, the current study examined authenticity as a mediatory mechanism in explaining the link between the habitual use of certain ER strategies and negative psychological symptoms. Participants were 391 university students (294 females) with a mean age of $21.5(S D=2.22)$. Reappraisal, suppression, and enhancing positive affect among ER strategies were included as predictor variables into the tested path model. Psychological ill-being was tested as the outcome variable, and it was computed on the basis of the participants' positive affect (reverse-coded), negative affect, depression, and stress levels. Trait authenticity was included as the mediator variable. The proposed model revealed a good fit to data, and the results suggested full support for the study predictions. Reappraisal negatively predicted psychological ill-being by leading to an increase in the authenticity levels. However, suppression intensified the negative psychological symptoms by lessening authenticity. Moreover, enhancing positive affect diminished psychological ill-being by fostering authenticity. Additionally, the mediating roles of specific authenticity dimensions were tested within the same model. Accordingly, 2 components of authenticity (i.e., self-awareness and autonomous behavior) mediated the relationship between ER and mental health. In the light of the present findings, it can be said that various ER strategies, which lead people to behave in accordance with their true selves, are protective in terms of psychological health. Further implications, limitations, and suggestions for future studies were discussed.
\end{abstract}

Keywords: Emotion regulation, reappraisal, suppression, enhancing positive affect, authenticity, psychological health 


\section{ÖZ}

İnsanlar duygularını kontrol etmek amacıyla çeşitli duygu düzenleme (DD) stratejilerinden yararlanırlar. Bu stratejilerden bazıları psikolojik iyi oluşu olumlu yönde etkilerken diğerleri olumsuz yönde etkileyebilmektedir. DD’nin işleyiş mekanizmalarının tespit edilmesi, duygu düzenlemenin psikolojik sağlık üzerindeki etkilerinin daha iyi bir şekilde anlaşılmasına yardımcı olabilir. Doğal duygusal tepkilerin değiştirilmesine dayalı olan kimi DD stratejileri bireylerin gerçekte oldukları kişi gibi davranmadıkları sonucuna varmalarına sebep olabilir. Ancak diğer DD stratejilerinden bazıları bireylerin özgünlüklerini muhafaza etmelerine yardımcı olabilir. Psikolojik iyi oluş açısından da önemi göz önünde bulundurularak mevcut çalışmada özgünlük değişkeni, belli DD stratejilerinin kullanımı ile olumsuz psikolojik belirtiler arasındaki ilişkiyi açıklamada işlevsel olabilecek bir aracı değişken olarak sınanmıştır. Çalışmanın katılımcıları yaş ortalaması $21.5(S S=2.22$ ) olan 391 (294'ü kadın) üniversite öğrencisidir. DD stratejilerinden yeniden değerlendirme, bastırma ve olumlu duygulanımı arttırma test edilen yol modeline yordayıcı değişkenler olarak dahil edilmiştir. Psikolojik rahatsızlık ilgili modelde sonuç değişken olarak incelenmiştir. Bu değişkene ait değer olumlu duygulanım (ters kodlanmış), olumsuz duygulanım, depresyon ve stres ölçümlerinden elde edilen puanlar toplanarak hesaplanmıştır. Özgünlük ise aracı değişken olarak ele alınmıştır. İstatistiki analizler sonucunda, önerilen yol modelinin kabul edilebilir uyum değerlerine sahip olduğu saptanmış ve bulguların çalışma hipotezlerinin tamamına destek sağladığ1 görülmüştür. Yeniden değerlendirme stratejisi özgünlüğü pekiştirerek psikolojik rahatsızlığı negatif yönde yordamıştır. Bastırma stratejisi ise özgünlüğü azaltarak olumsuz psikolojik çıktıları pozitif yönde yordamıştır. Bunun yanı sıra, olumlu duygulanımı arttırma stratejisi özgünlük değişkeni üzerinde bir artışı tetikleyerek psikolojik rahatsızlığı negatif yönde yordamıştır. Ayrıca aynı model çerçevesinde belirli özgünlük boyutlarının aracı rolü de irdelenmiştir. Buna göre özgünlüğün iki boyutunun (öz-farkındalık ve özerk davranış) DD ve psikolojik sağlık arasındaki ilişkiye aracılık ettiği görülmüştür. Mevcut bulgular 1şığında, insanları gerçekte oldukları kişi gibi davranmaya yönelten çeşitli DD stratejilerinin psikolojik sağlık açısından koruyucu olduğu söylenebilir. Bulgulara ilişkin diğer çıkarımlar, çalışmanın kısıtlılıkları ve gelecek çalışmalar için öneriler tartışılmıştır.

Anahtar Kelimeler: Duygu düzenleme, yeniden değerlendirme, bastırma, olumlu duygulanımı arttırma, özgünlük, psikolojik sağlık 
When individuals are uneasy with the type, intensity, expression, or length of their affective states, they may want to modify the inappropriate aspect of their emotions. This process is called emotion regulation (ER; Gross, 1998, 2014, 2015). Various ER strategies can be employed to exert control over emotions. Two of those strategies have been widely addressed in the literature: cognitive reappraisal, which is the process of re-interpretation of the emotion-eliciting situation/stimulus to alter its affective influence, and expressive suppression, which is the inhibition process of emotion-expressive behaviors such as facial expressions, gestures, or verbal expressions (Gross, 1998, 2014, 2015; Gross \& John, 2003). Another commonly used ER strategy is savoring, which is sharing one's positive emotions with others to enhance one's existing positive affectivity (Quoidbach, Berry, Hansenne, \& Mikolajczak, 2010). The ways in which people regulate their emotions is influential on their well-being. The literature consistently demonstrates that reappraisal and savoring are beneficial for psychological health, whereas suppression is a threat to it (See Niedenthal \& Ric, 2017; Quoidbach et al., 2010). However, less attention has been given to understand why some ER strategies are beneficial for, but some others are detrimental to the human psyche. In an attempt to fill this gap, the chief concern in the present study is to unearth the underlying mechanisms behind the ill-being implications of the habitual use of specific ER strategies.

During an ordinary ER episode, individuals actively monitor their emotion regulatory act and evaluate whether it parallels to their values and general self-views (English \& John, 2013). For example, people go through a self-evaluation process while suppressing the behavioral manifestations of their emotional experiences. That evaluation, especially in the use of certain ER tactics, might lead people to perceive an acute mismatch between their inner world (true selves) and outer behaviors. According to English and John (2013), if a person experiences such incongruence repeatedly, it can pose a threat to one's dispositional authenticity, and thus contribute to negative psychological symptoms in the long run. Given the significance of ER for the self-related processes, authenticity (i.e., behaving in accordance with one's true self; Kernis \& Goldman, 2006) was chosen in the present study as a possible explanatory mechanism in the ER and mental health link.

At first glance, ER seems like an interruption in the natural process of emotional experience/response, and relatedly, it can be considered as a threat to authenticity (Anderson, Chen, \& Ayduk, 2019). As a matter of fact, suppression, which creates a misalign- 
ment between one's felt and expressed emotions, negatively predicted authenticity (English \& John, 2013). On the contrary, a perspective-based reappraisal strategy caused an increase in people's authenticity levels by lessening their awareness that they were modifying their natural emotions (Anderson et al., 2019). As is evident, regulatory efforts can either interfere or promote authentic functioning depending on the ER strategy. Given also its contribution to psychosocial functioning (e.g., Kernis \& Goldman, 2006; Ryan, LaGuardia, \& Rawsthorne, 2005), authenticity was hypothesized to mediate the relationship between particular ER tactics and psychological ill-being in the current study. Mental health has been considered for a long time as the mere absence of psychopathological symptoms. However, today, mental health is viewed as both the absence of mental illnesses and the presence of psychosocial and emotional well-being (Keyes, 2005; Westerhof \& Keyes, 2010). Accordingly, in the present study as well, psychological ill-being was conceptualized as both the presence of certain mental illness (i.e., depression) and the absence of emotional well-being (i.e., lack of positive affect, and frequent experience of stress and negative affect). Three ER strategies, namely, suppression, reappraisal, and enhancing positive affect, were addressed to gain a comparative understanding about their possible contributions to both authenticity and psychological ill-being.

\section{Emotion Regulation Strategies and Their Implications for Psychological Health}

In an attempt to intervene the "spontaneous flow of their emotions" (Koole, 2009, p. 6), people utilize certain ER strategies to intensify, retain, or lessen their positive or negative emotions. The process model of ER classifies the different regulatory tactics into two general categories: antecedent-focused vs. response-focused strategies (Gross, 1998, 2014). Antecedent-focused strategies are used to prevent a particular emotional experience in terms of type or intensity. Accordingly, people may avoid entering certain situations that might elicit undesirable emotions, divert their attention from the emotion-arousing aspect of such situations, or they may revise the personal meaning they attach to that aspect. On the contrary, individuals use response-focused strategies after a particular emotion is fully generated. Correspondingly, people may try to regulate their expressive behaviors, suppress the related emotional thoughts, or they may prefer to disclose their emotions to others (Niedenthal \& Ric, 2017). While reappraisal is an antecedent-focused strategy (Gross, 2014), suppression and savoring are response-focused strategies (Niedenthal \& Ric, 2017). 
Psychosocial implications of the usage of reappraisal and suppression tactics have been examined comparatively in the literature. Reappraisal was related to greater experience and expression of positive emotions, and lesser experience and expression of negative emotions, while suppression had the exact opposite correlational patterns of reappraisal (Gross \& John, 2003). Reappraisal was associated with decreased depression, and heightened life satisfaction, optimism, and self-esteem (Garnefski, Kraaij, \& Spinhoven, 2001; Gross \& John, 2003). Similarly, reappraisal also contributed to healthier interpersonal relatedness as indicated by increased social sharing, relationship closeness, peer liking, social support (Gross \& John, 2003), and marital satisfaction (Mazzuca, Kafetsios, Livi, \& Presaghi, 2018). However, suppression negatively influenced psychosocial functioning in contrast to reappraisal (Gross \& John, 2003; John \& Gross, 2004). The protective impact of reappraisal vis-à-vis the dampening effect of suppression was cross-culturally confirmed as well (See Glidden, Billings, \& Jobe, 2006; Haga, Kraft, \& Corby, 2009).

According to Broaden-and-Build Theory, positive emotions enable people to look at the world from a broader perspective and to come up with creative solutions to their problems (Fredrickson, 2001, 2003). Relatedly, the maintenance of positive affective states is also critical to ER processes. Displaying positive emotions behaviorally, being present and focusing on the current positive emotions, social sharing of positive experiences, and conducting positive mental time travel can be mentioned as the savoring strategies that are used to enhance positive affect (Bryant, 1989; Gentzler, Palmer, \& Ramsey, 2016; Quoidbach et al., 2010). Frequent use of such strategy was related to a decrease in the experience of negative emotions, and to an increase in the likelihood of experiencing more positive emotions (Livingstone \& Srivastava, 2012; Quoidbach et al., 2010). Savoring also contributed to life satisfaction (Quoidbach et al., 2010), well-being (Livingstone \& Srivastava, 2012), daily happiness (Jose, Lim, \& Bryant, 2012), and resilience in the face of stressful life events (Tugade \& Fredrickson, 2007). When it comes to interpersonal functioning, savoring was linked to various positive relationship outcomes such as, trust, passion, intimacy, dyadic satisfaction, and reduced conflicts (Costa-Ramalho, Marques-Pinto, Ribeiro, \& Pereira, 2015; Samios \& Khatri, 2019).

In consideration of the aforementioned studies, it is obvious that there is a well-established link between ER strategies and (im)proper psychological functioning. Most of the researchers have focused on the mediatory role of ER strategies in explaining the 
psychosocial outcomes (See Kirwan, Svenson, Pickett, \& Parkhill, 2019; Pepping, Duvenage, Cronin, \& Lyons, 2016). However, the mechanism explaining how ER strategies are related to those outcomes is mostly overlooked, and only a limited number of studies have been held to understand the nature of this link. An exceptional study conducted on Chinese soldiers revealed that social support and resilience together mediated the relationship between cognitive ER and acute stress responses (Cai et al., 2017). Another study by English and John (2013) also showed that the link between suppressive tendencies and poor social functioning was mediated via decreased levels of authenticity. However, the mediatory role of authenticity for the reappraisal-social functioning link was not confirmed in the same study. The present research extended the study of English and John (2013) in three different ways. First, in addition to reappraisal and suppression, savoring strategy was also examined as the predictor variable. Second, instead of social functioning, psychological ill-being was addressed as the outcome variable. Third, by not reducing authenticity to a relational construct, the current study treated authenticity as a multidimensional construct.

\section{Emotion Regulation Strategies and Authenticity}

Philosophical accounts of authenticity date back to the Ancient Greek philosophers, such as Socrates and Aristotle, and still survive today with the contributions of the $20^{\text {th }}$ century existential philosophers, such as Jean-Paul Sartre and Martin Heidegger. These different philosophical perspectives often assert that authenticity includes thought-action uniformity, and an individual can derive a sense of authenticity only by listening to one's innermost self, but not by complying with the societal standards (Kernis \& Goldman, 2006). Similar themes are also existent in psychological perspectives on authenticity. For example, according to Self-Determination Theory (Deci \& Ryan, 2000), only autonomous and self-determining individuals can function authentically in their daily lives. The term self-actualization from humanistic psychology (Rogers, 1961) also shaped the contemporary psychological understanding of authenticity (Kernis \& Goldman, 2006). A fully-functioning individual is characterized by openness to novel experiences, full presence in the moment, a trust in and guidance by one's inner experiences, freedom even in the most restricting environments, and creativity as opposed to the adoption of the most traditional modes of behavioral responses (Cloninger, 1993).

In line with the above-summarized philosophical and psychological perspectives on authenticity, the construct is defined as "the unobstructed operation of one's true- or 
core self in one's daily enterprise" in the psychology literature (Kernis \& Goldman, 2006 , p. 294). Rather than being a unitary process, authenticity can be divided into four interrelated constituents, namely, self-awareness, unbiased processing, autonomous behavior, and relational orientation (Kernis \& Goldman, 2006). First, the self-awareness component fosters acceptance of and trust in one's multifaceted (possibly inconsistent) self-aspects and renders the integration of superficial discrepancies into one's self. Second, unbiased processing is related to having a neutral stance about one's weaknesses and strengths. Third, contrary to external control, behavioral authenticity entails acting in line with one's true values, desires, or preferences. Fourth, based on relational orientation, an authentic person feels free and natural to express one's true self in intimate relationships with no fear of being criticized. Authenticity was negatively linked to negative affect (Goldman \& Kernis, 2002; Kuyumcu \& Kabasakaloğlu, 2018) and contingent self-esteem (Goldman \& Kernis, 2002), stress and physical symptoms (Kernis \& Goldman, 2006; Ryan et al., 2005), and verbal defensiveness (Lakey, Kernis, Heppner, \& Lance, 2007). In contrast, it was positively associated with positive indicators of mental health, such as positive affect (Kuyumcu \& Kabasakaloğlu, 2018), general self-esteem, life satisfaction (Goldman \& Kernis, 2002), and subjective vitality (Ryan et al., 2005).

Besides those personal effects, authenticity is also impactful on how one interacts with others. A study on 62 heterosexual couples revealed that authenticity contributed to positive relationship behaviors (e.g., trust, self-disclosure), which in turn led to an increase in relationship quality (Brunell et al., 2010). Moreover, being true to oneself also safeguards people from the adverse effects of interpersonal conflicts (Wickham, Williamson, Beard, Kobayashi, \& Hirst, 2016). When it comes to workplace literature, authentically expressing emotions to customers was found to be positively related to customer satisfaction (Grandey, Fisk, Mattila, Jansen, \& Sideman, 2005). Taken together, authenticity emerges as an important predictor of better psychosocial functioning in various contexts.

The literature yields several psychological antecedents of authenticity including promotion orientation (Kim, Chen, Davis, Hicks, \& Schlegel, 2019) and social power (Kraus, Chen, \& Keltner, 2011). A study on the autobiographical narratives of authentic experiences revealed that authentic moments were associated with more positive affect, and inauthentic ones with more negative affect (Lenton, Bruder, Slabu, \& Sedikides, 
2013). This was a correlational study, and it hinders researchers from delineating whether affect is linked to authenticity as an outcome or a predictor variable. However, both experimental attempts (Lenton, Slabu, Sedikides, \& Power, 2013) and experience sampling evidence (Cooper, Sherman, Rauthmann, Serfass, \& Brown, 2018) demonstrated that positive affect would yield an increase in the momentary experience of authenticity. Even though there are studies which address affect as a precursor of authenticity, the current study examined both positive and negative affect (indicators of emotional well-being) as an outcome of authenticity just like Kuyumcu and Kabasakaloğlu (2018) did.

Recent studies (Anderson et al., 2019; Greenaway \& Kalokerinos, 2017, 2019) also provide a reasonable basis for questioning the role of ER processes as another antecedent of authenticity. According to Greenaway and Kalokerinos (2019), people might hold different emotion goals in a given situation. As options, they may prefer both to experience and express their emotions or neither experience nor express them. Alternatively, they can just experience but not express their emotions or they may choose to just express but not experience them. The emotion goals of experience and expression can be consistent (e.g., feeling and showing) or inconsistent (e.g., feeling but not showing). Openly expressing one's emotions is named emotional authenticity, and emotionally authentic people have social advantages given the fact that authenticity communicates trust in the interpersonal realm (Greenaway \& Kalokerinos, 2017, 2019). However, deliberate attempts to modify one's natural feelings during a typical ER process can pose a threat to authenticity (Anderson et al., 2019). Yet, recent studies (Anderson et al., 2019; English \& John, 2013) show that ER by itself is not harmful for authentic functioning, but the type of ER determines whether regulatory efforts impair or strengthen authenticity. ER strategies which result in an alignment between emotional experience and its expression (i.e., emotional authenticity), and which are not perceived as an intrusion to the natural course of emotions seem to help people preserve their authenticity (Anderson et al., 2019). Instead of focusing on emotional authenticity as a momentary experience, the present study examined authenticity as a dispositional level construct. According to English and John (2013), repeated experience of incongruence between one's emotional experience and its behavioral expression might lead people to develop a chronic sense of inauthenticity in the long run. In light of this reasoning, habitual use of certain ER strategies which create an inner-outer (mis)match can aptly be taken as a possible predecessor of (in)authentic personality. 
Since emotional experience and expression rules change from one culture to another (Kitayama, Markus, \& Kurokawa, 2000; Matsumoto, 1990), it is possible that culture has an influence on the link between different ER strategies and authenticity. For example, in comparison to Western cultures, East Asian cultures might not put a high emphasis on aligning their subjective emotional experience and its external expression (Peng \& Nisbett, 1999). As a result, the link between response-focused ER strategies (such as suppression or savoring) and authenticity might not hold true for non-individualistic cultures. However, the work of English and John (2013) revealed that even in Asian Americans and Chinese people, habitual use of suppression led to an increase in subjective inauthenticity, which in turn disrupted people's social functioning. Here, it can be asserted that Asian values do not alleviate the interpersonal costs of suppression. Instead of relationship quality, mental health was addressed as an outcome variable in the current study. Moreover, how culture shapes the nature of the association between authenticity and mental health has been widely considered in the literature as well. For example, the happiness of individuals from individualistic cultures was found to be dependent on the consistency between one's internal states and behaviors (i.e., authenticity; Kifer, Heller, Perunovic, \& Galinsky, 2013). On the contrary, meta-analytical findings by Sutton (2020) showed that collectivism weakened the positive association between authenticity and well-being. What is more, authenticity was found to be negatively correlated with subjective well-being in the Philippines, which represents a collectivistic culture (Datu \& Reyes, 2015).

The current study context, Turkey, is also classified as a collectivistic culture even though it is located at the middle of the individualism-collectivism continuum (Hofstede, 2001). According to the Balanced Integration and Differentiation Model (İmamoğlu, 1998), individuals from both individualistic and collectivistic cultures have two integral psychological needs: intrapersonal differentiation (i.e., being differentiated from others with one's unique potential), and interpersonal integration (i.e., maintaining one's connectedness to others). Simultaneous fulfillment of both needs is critical to optimal psychological functioning, and people who are high on both orientations (representing the individuated-related self-type) are said to have a balanced self-construction. A study by İmamoğlu, Günaydın and Selçuk (2011) showed that Turkish university students with a balanced self-orientation were the most authentic persons in the sample. Given the finding that balanced self-orientation was associated with higher life satisfaction and 
psychological well-being (İmamoğlu \& Beydoğan, 2011), a positive association between authenticity and mental health in the Turkish samples can be expected. The findings by Kuyumcu and Kabasakaloğlu (2018) and Aydoğan, Özbay and Büyüköztürk (2017) confirm this expectation. However, these findings seem inconsistent with the above-mentioned empirical findings from the Philippines (Datu \& Reyes, 2015). In this regard, there is an emerging need to expand the empirical knowledge on culture-sensitive constructs such as authenticity and well-being in various cultural contexts. The present study added ER as a predictor variable into this equation and tested the mediatory role of authenticity in the ER-mental health link in the Turkish context.

The current study proposed that authenticity, which accompanies certain ER attempts, could play a protective role for psychological health. Accordingly, in a cross-sectional design research, authenticity was examined as a mediator between three different ER strategies and negative psychological symptoms (see Figure 1).

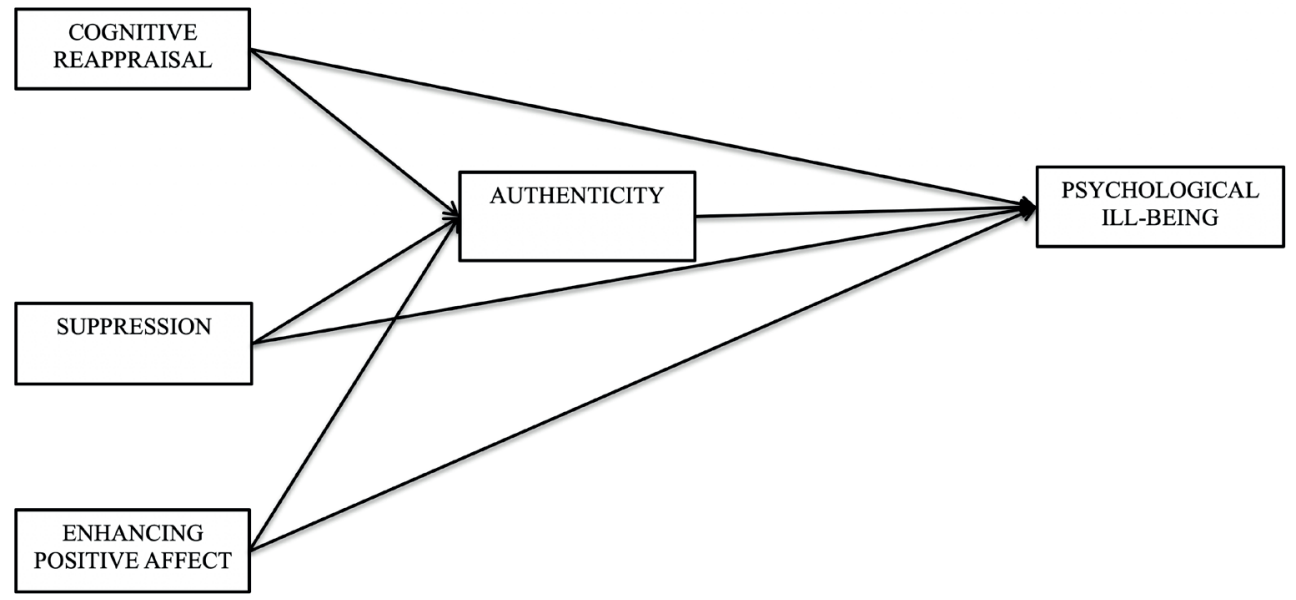

Figure 1. Hypothesized Model Predicting the Psychological Ill-being.

The contributions of the present study are at least threefold. Firstly, underlying mechanisms lying behind the link between ER and well/ill-being have not been adequately addressed in the literature. Testing authenticity as an explanatory mechanism, this research could fill the related gap. Secondly, the three predictor variables in the current path model are cognitive reappraisal as an antecedent-focused ER strategy, and expressive suppression and enhancing positive affect as response-focused ER strategies. Such a diverse set of ER mechanisms could provide a comparative understanding about 
the role of ER in predicting people's authenticity levels, and thus psychological distress. Thirdly, the current work could contribute to the existing literature by examining whether the expected relationships among the study variables hold true in the Turkish context, which traditionally represents a collectivistic culture.

When an individual suppresses the public expression of one's affective experiences, it causes incongruence between one's inner and outer world, and thus, the feelings of inauthenticity (English \& John, 2013). In support of this reasoning, regulating emotions via suppression resulted in subjective inauthenticity, which in turn led to an increase in negative affect (Gross \& John, 2003), and a decrease in psychological well-being and relationship quality (English \& John, 2013; Impett et al., 2012). Hence, the first hypothesis of the present study is that:

H1: Suppression would positively contribute to psychological ill-being by leading to a decrease in authenticity.

Ford and Troy (2019) speculated that reappraisal could potentially lead to the feelings of inauthenticity given the fact that it involves disclaiming the value of one's original interpretation of a situation. However, reappraisal was found to be unrelated to authenticity in the studies by English and John (2013), and Lenton, Slabu et al. (2013). In an examination of the assessment tools of authenticity in those studies, it can be stated that English and John (2013) treated authenticity as a relational phenomenon, whereas Lenton, Slabu et al. (2013) measured it as a state-level construct. In this regard, there is a value in re-testing the link between ER strategies and authenticity with a multi-componential approach to the latter. Specifically, in accordance with Kernis and Goldman's (2006) approach, in the present study, authenticity was addressed by including its dimensions of self-awareness, unbiased processing, autonomous behavior, and relational orientation. Findings from emotional labor literature can be informative about the possible association between reappraisal and authenticity. Many salespeople have to keep a smiling face even in the presence of demanding customers. The term deep acting is used to refer to the effort in modifying one's feelings to show the desired emotion in the work setting, and doing so requires mostly reappraising the work events (Grandey, 2000). A study by Brotheridge and Lee (2002) showed that deep acting contributed to an increase in authenticity, which in turn alleviated the emotional exhaustion of employees. Besides, one recent experimental study compared the effect of emotion-focused and per- 
spective-based reappraisal strategies on authenticity (Anderson et al., 2019). The former is related to an explicit goal of changing one's emotions, whereas the latter is adopting a new viewpoint regarding the emotion-evoking situation. According to the study results, people reported higher authenticity and they were also rated as being more authentic by independent observers after regulating their emotions via perspective-based compared to emotion-focused reappraisal. What is more, the link between perspective-based reappraisal and state authenticity was mediated through a decreased awareness that participants were changing their naturally-occurring emotions. As is clear, if people are natural and successful at changing the meaning of an emotion-evoking event, their unwanted emotions will be transformed into desirable ones. In the end, they can continue to remain themselves in their emotional responses. Hence, the second hypothesis of the present study is that:

H2: Reappraisal would negatively predict psychological ill-being by leading to an increase in authenticity.

When it comes to savoring strategy as an effective tactic in the up-regulation of positive emotions (Livingstone \& Srivastava, 2012; Quoidbach et al., 2010), its link to authenticity has not been empirically verified yet. However, people who were in a positive mood reported higher levels of state authenticity than those who were in a negative mood (Lenton, Slabu et al., 2013). Moreover, momentary positive experiences such as happiness and self-esteem were strongly related to experienced authenticity (Cooper et al., 2018). As positive affective states are speculated to be crucial for the access to one's core self and intrinsic goal strivings (Koole \& Kuhl, 2003), frequent use of the strategy of enhancing positive affect might also be associated with authenticity. Thus, the third hypothesis of the present study is that:

H3: Enhancing positive affect would negatively contribute to psychological ill-being by leading to an increase in authenticity.

The main hypotheses of the current study were based upon global authenticity scores. However, as stated above, according to Kernis and Goldman (2006), authenticity includes four separate and interrelated sub-components. Anderson et al. (2019) speculated that different facets of authenticity might be differentially related to different ER techniques. Given the empirical scarcity in the literature, it can be an immature attempt to come up with specific hypotheses about the nature of those relationships. Yet, as an 
exploratory concern in the current study, the mediatory roles of the various dimensions of authenticity were also tested.

\section{METHOD}

\section{Participants}

Participants were 391 undergraduate psychology students who study at a state university in Ankara. Convenience sampling technique was preferred. The study was announced in the classrooms by the current researchers, and volunteers participated in the study through the Internet. The data was collected with the help of Qualtrics survey tool. All participants received an informed consent form before the data collection, and they got extra course credit for their participation. There were 294 female (75.19\%) and 97 male students $(24.81 \%)$ in the study. Such a distribution corresponds to the usual gender distribution of psychology undergraduates in Turkey (Sümer, Helvaci, \& Misirlisoy, 2013). Participants' ages ranged between 18 and $38(M=21.50, S D=2.20)$.

\section{Measures}

Emotion Regulation Questionnaire. Gross and John (2003) developed an Emotion Regulation Questionnaire to assess the habitual use of suppression (as a response-focused ER strategy) and reappraisal (as an antecedent-focused ER strategy). The Turkish adaptation of the scale was carried out by Eldeleklioğlu and Eroğlu (2015). The scale consists of 10 items. Individuals evaluate themselves on a 7-point Likert-type scale (1 = Strongly Disagree, $7=$ Strongly Agree). In the present study, internal consistencies of the subscales were acceptable both for suppression $(\alpha=.80)$ and reappraisal $(\alpha=.88)$.

Enhancing Positive Affect Scale. Hofmann, Carpenter and Joshua (2016) developed an Interpersonal Emotion Regulation Questionnaire (IERQ) to assess the tendency to use different interpersonal ER strategies (i.e., enhancing positive affect, perspective taking, soothing, and social modeling). Yücel, İnan, Süsen, Karanfil and YalçınkayaAlkar (2017) translated this scale into Turkish. To evaluate the habitual use of savoring (as a response-focused ER strategy), enhancing positive affect subscale of IERQ (e.g., "I like being in the presence of others when I feel positive because it magnifies the good feeling") was used in the current study. This subscale consists of 5 items rated through a 5-point Likert scale ranging from $1=$ Strongly Disagree to $5=$ Strongly Agree. It revealed a satisfactory internal consistency in the current study $(\alpha=.90)$. 
Authenticity Scale. Kernis and Goldman (2006) developed a scale to assess the authenticity levels of individuals. It is a 45-item 7-point Likert scale, ranging from $1=$ Strongly Disagree to 7 = Strongly Agree. A short form of this measure with 27-items was adapted into Turkish by İmamoğlu et al. (2011), and this short form was utilized in the present study. As in the original form, the Turkish version of the scale also had 4 subscales, namely, self-awareness (e.g., "For better or for worse I am aware of who I truly am."), unbiased processing (e.g., "If someone points out or focuses on one of my shortcomings, I quickly try to block it out of my mind and forget it."; a reverse-coded item), autonomous behavior (e.g., "I find it easy to pretend to be something other than my true self."; a reverse-coded item), and relational orientation (e.g., "In general, I place a good deal of importance on people I am close to understanding who I truly am."). In their original study, Kernis and Goldman (2006) attained the Cronbach alpha score of .90 for the total score of authenticity scale, and confirmed that four first-order authenticity factors were explained by a general, higher-order authenticity factor. Therefore, in this study, authenticity was included as a total score $(\alpha=.85)$ to test the three main hypotheses. For exploratory purposes, four separate authenticity dimensions were also tested for their mediatory roles. The Cronbach's alphas were .78 for self-awareness, .89 for unbiased processing, .66 for autonomous behavior, and .76 for relational orientation.

Multidimensional Scale of Perceived Social Support. It was developed by Zimet, Dahlem, Zimet and Farley (1988) to assess the degree of perceived social support that individuals receive from various interpersonal resources. Eker and Arkar (1995) adapted the scale into Turkish. It is a 12-item 7-point Likert scale with three subscales (fami$l y$, friends and significant others). The total score $(\alpha=.89)$ was used as a control variable in the current study to parse out the unique role of enhancing positive affect (which is also interpersonal by its very nature) in predicting psychological ill-being.

Psychological Ill-being. Three different scales, namely, Positive Affect and Negative Affect Scale (PANAS), Center of Epidemiologic Studies-Depression Scale (CES-D), and Perceived Stress Scale (PSS) were utilized to assess psychological ill-being. The first scale PANAS was developed by Watson, Clark and Tellegen (1988) to measure the affective status (positive and negative affect) of individuals and adapted into Turkish by Gençöz (2000). The scale has 20 items, and individuals evaluate their affective status (e.g., excited, upset) on a 7-point Likert scale. The Cronbach's alpha scores were found to be .84 for positive affect and .85 for negative affect in the current 
study. Items of the positive affect subscale were reverse coded in the calculation of the psychological ill-being score. The second scale CES-D was developed by Radloff (1977) to assess the depression levels of individuals. The Turkish adaptation study of this scale was carried out by Tatar and Saltukoğlu in 2010. It is a 4-point Likert scale with 20-items. The Cronbach's alpha was .90 for the present study. When it comes to the third scale PSS, it was developed by Cohen, Kamarck and Mermelstein (1983) to measure how much stress individuals experience in their daily lives. The scale was adapted into Turkish by Eskin, Harlak, Demirkıran and Dereboy (2013). It is a 5-point Likerttype scale with 14 items. Internal consistency of the scale was .84 in the current study.

As stated before, in accordance with the suggestions of Keyes (2005) and Westerhof and Keyes (2010), psychological ill-being was conceptualized as both the presence of certain psychopathological symptoms (i.e., depression), and the absence of emotional well-being (i.e., lack of positive affect, and frequent experience of negative affect and stress) in the present study. A principal-components factor analysis on these four different scales revealed a single psychological ill-being factor, accounting for $57 \%$ of the variance, with the positive affect loading having an absolute value of .44, and the remaining three loadings having an absolute value greater than .77. All the total scores coming from them were converted into $z$-scores, and a composite psychological ill-being score $(\alpha=.73)$ was computed by adding them to each other (for other studies which also calculated a global mental health indicator with a similar additive approach, see La Guardia, Ryan, Couchman, \& Deci, 2000; Reis, Sheldon, Gable, Roscoe, \& Ryan, 2000).

\section{Procedure}

Prior to data collection, ethical approval was obtained from Ankara Y1ldırım Beyazit University Ethical Committee. Following the approval, informed consent and scales were uploaded to Qualtrics and a link was created. The link of the study was spread on social media and class groups to reach participants. It took approximately 20-25 minutes to complete the survey.

\section{Data Analysis}

The main aim of the current study was to explore whether the link between various ER strategies and psychological ill-being was mediated through authenticity. Accordingly, three main hypotheses were developed and combined into a path model. The current- 
ly-proposed model was tested with a path analysis through AMOS by using the maximum likelihood method. Model fit was assessed based on chi-square statistic, the chi-square to the degrees-of-freedom ratio $\left(\chi^{2} / \mathrm{df}\right)$, comparative fit index (CFI), the goodness of fit index (GFI), and root-mean-square error of approximation (RMSEA). A good fit requires a non-significant $\chi^{2}$ statistic, and values that are less than 3 for $\chi^{2} / \mathrm{df}$ ratio (Byrne, 2006), greater than or equal to .95 for CFI, lower than or equal to .06 for RMSEA (Hu \& Bentler, 1999), and greater than .95 for GFI (Shevlin \& Miles, 1998). The significance of each mediated effect was examined to test the three different mediation hypotheses. Since bootstrap tests of indirect effects are "always more powerful than Sobel's tests" (Zhao, Lynch, \& Chen, 2010, p. 202), 2000 bootstrapping tests were performed to attain 95\% confidence intervals (CI) for each indirect effect. If those bootstrapping CIs did not include zero, this would suggest significance for the related indirect effects.

For exploratory purposes, the aspects of authenticity which were more critical in mediating the link between ER and psychological ill-being were also questioned. To examine this, the scores coming from the different sub-scales of authenticity were used. However, since they were subscales of a single authenticity score, multicollinearity might pose a threat to the model estimates in the current analysis. Relatedly, a collinearity diagnostic was performed. In consideration of typically used cutoff values (Field, 2018), the largest VIF value did not exceed or approach to 10, or the tolerance did not approach or drop below 0.10 , which indicated the absence of a multicollinearity problem.

\section{RESULTS}

Table 1 presents the zero-order correlations among the study variables and descriptive statistics. All three ER strategies were significantly correlated with authenticity. Authenticity was negatively related to suppression $(r(289)=-.42, p<.01)$, whereas it was positively associated with reappraisal $(r(289)=.36, p<.01)$ and enhancing positive affect $(r$ $(289)=.41, p<.01)$. As predicted, authenticity was also negatively linked to psychological ill-being $(r(289)=-.43, p<.01)$. There was no gender difference in terms of authenticity scores, $(F(1,389)=3.31, p>.05)$. However, psychological ill-being was negatively related to age $(r(289)=-.20, p<.01)$, social support $(r(289)=-.37, p<.01)$, and gender $(r(289)=-.11, p<.05)$. Females $(M=.19, S D=3.02)$ had greater psychological ill-being scores than males $(M=-.57, S D=2.77), F(1,389)=4.80, p<.05$. Accordingly, age, gender, and social support were controlled in the hypothesized model. 


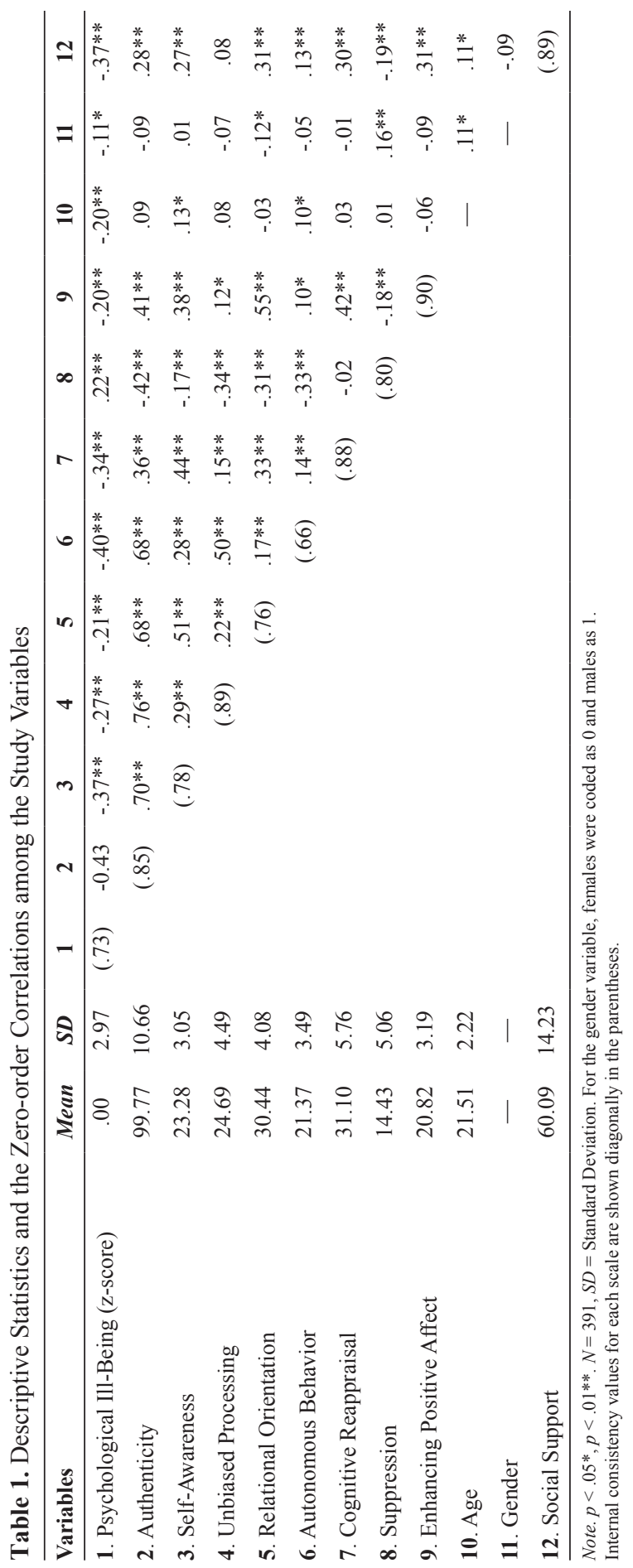




\section{Hypothesis Testing: Understanding the Mediatory Role of Authenticity}

To test the mediation effect of authenticity, the steps of mediation analysis recommended by Zhao et al. (2010) were followed. As a first step, all parameters (both direct and indirect effects) were estimated in the currently-proposed path model, and the bootstrap tests of all indirect effects were held. In the second step, the type of mediation for each indirect route was classified in consideration of the significance and the sign of both direct and indirect effects. As opposed to Baron and Kenny's (1986) classification of full, partial, and no mediation, Zhao et al. (2010) offered a different typology for mediation and non-mediation. Accordingly, indirect-only mediation occurs when indirect effect is significant, but direct effect is not. When both indirect and direct effects are significant, one should consider the sign of the product term obtained by multiplying the indirect and direct effects. If the product term has a negative sign, this reflects a competitive mediation, and if that term has a positive sign, this reflects a complementary mediation. However, when direct effect is significant, but indirect effect is not, this indicates direct-only non-mediation. When none of those effects are significant, this is named no-effect non-mediation.

All three hypotheses were assessed in a path analysis. The currently-proposed path model showed a good fit to data $\left(\chi^{2}(8)=10.78, p>.05, \chi^{2} / \mathrm{df}=1.35, \mathrm{CFI}=.99, \mathrm{GFI}=\right.$ .99 , and RMSEA $=.03$ ). Standardized path coefficients are summarized in Figure 2.

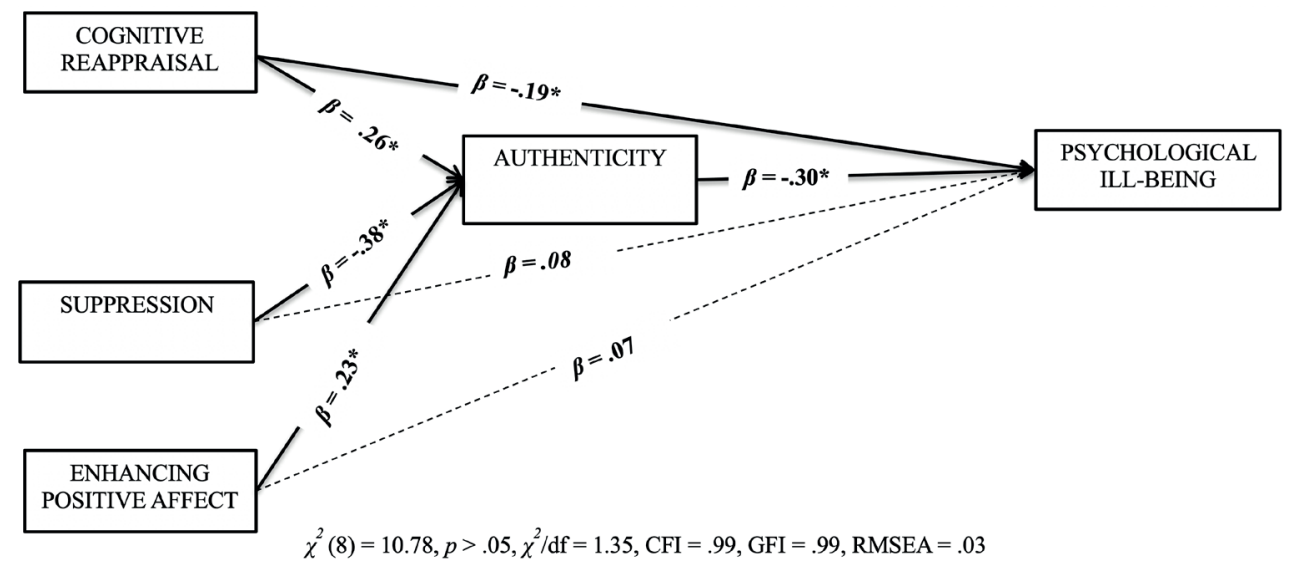

Figure 2. Path Model Testing the Current Hypotheses.

Note. The model was run controlling for the impacts of age, gender, and social support. Dashed lines represent non-significant paths, and straight lines represent significant paths. $* p<.01$. 
The direct effects of suppression $(B=.05, S E=.03, p>.05)$ and enhancing positive affect $(B=.07, S E=.05, p>.05)$ on psychological ill-being were non-significant, while the direct effect of cognitive reappraisal on psychological ill-being $(B=-.10, S E=.03$, $p<.01)$ was statistically significant. Additionally, authenticity was negatively related to pscyhological ill-being $(B=-.08, S E=.01, p<.01)$. In support of $H 1$, the indirect effect of suppression on psychological ill-being through authenticity $(B=.07, S E=.01, p<$ .01) was significant. As its indirect effect was significant, but its direct effect was not, the results indicated an indirect-only mediation for suppression. With respect to $H 2$, authenticity significantly mediated the association of cognitive reappraisal with psychological ill-being $(B=-.04, S E=.01, p<.01)$. As both the direct and indirect effects of cognitive reappraisal were significant, and the product of them had a positive sign, the results revealed a complementary mediation for this ER tactic. In relation to $H 3$, authenticity $(B=-.06, S E=.01, p<.01)$ also emerged as a significant mediator in the relationship between enhancing positive affect and psychological ill-being. Enhancing positive affect had a significant indirect effect, but a non-significant direct effect, which suggested an indirect-only mediation for this ER strategy. R-square statistics demonstrated that $31 \%$ of the variance in psychological ill-being was explained by the current model.

In addition to the proposed path model, an alternative model where ER strategies mediated the relation between authenticity and psychological ill-being was also tested. The alternative model yielded not-too-bad fit indices for the data $\left(\chi^{2}(11)=66.18, p>\right.$ $.05, \chi^{2} / \mathrm{df}=6.02, \mathrm{CFI}=.89, \mathrm{GFI}=.96$, and $\left.\mathrm{RMSEA}=.11\right)$. However, the original model revealed a better fit to data than the alternative model $\left(\Delta \chi^{2}(3, N=391)=55.40, p<\right.$ $.01)$. Accordingly, the currently-proposed model was retained.

\section{Exploring the Mediatory Roles of Different Aspects of Authenticity}

As an exploratory concern, four components of authenticity (i.e., self-awareness, unbiased processing, autonomous behavior, \& relational orientation) were also tested for their mediatory roles in the present study. Accordingly, instead of total authenticity, the sub-dimensions of authenticity were included as mediatory variables into the currently proposed model. This model also yielded a good fit to data $\left(\chi^{2}(13)=25.30, p<.05, \chi^{2} /\right.$ $\mathrm{df}=1.95, \mathrm{CFI}=.99$, GFI $=.99$, and RMSEA $=.05)$. Standardized path coefficients are summarized in Figure 3. 


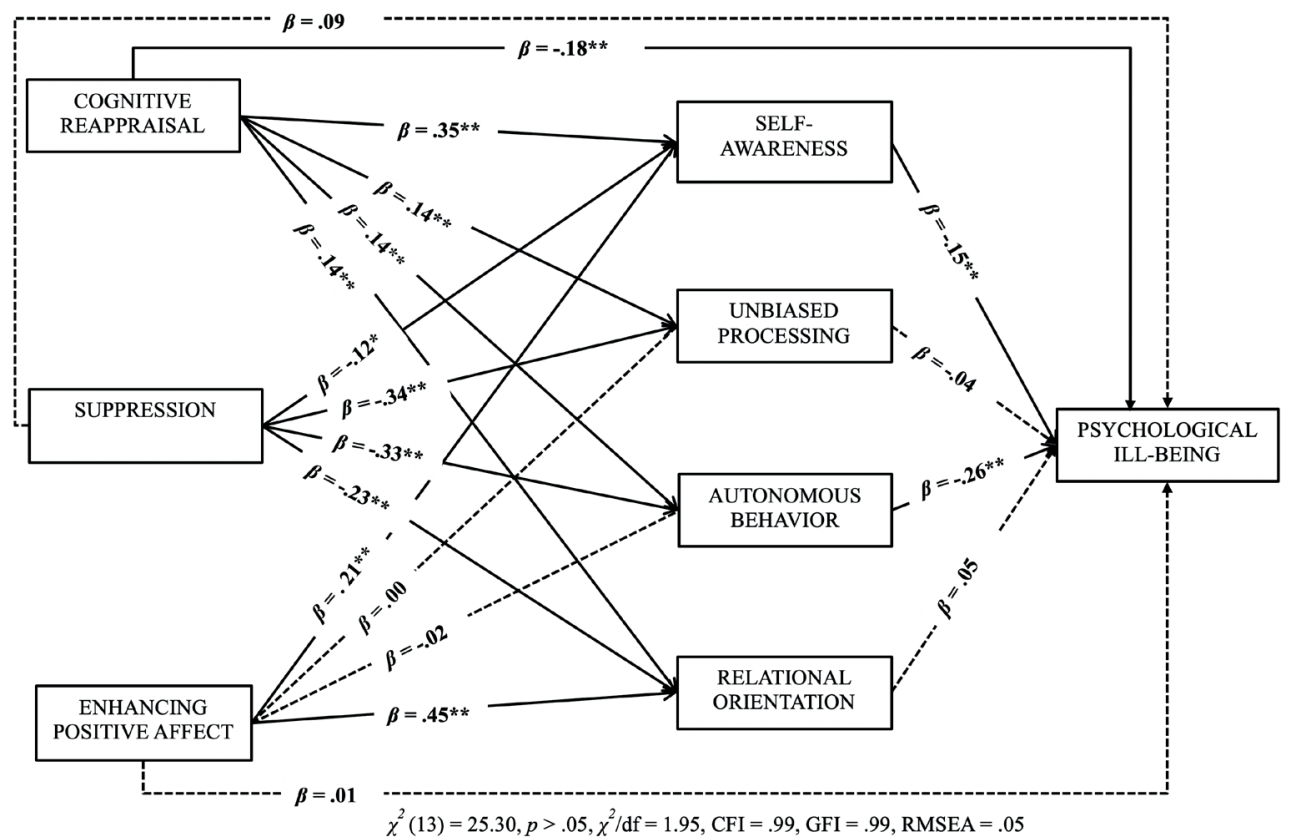

Figure 3. Path Model Testing the Mediatory Roles of Various Facets of Authenticity.

Note. The model was run controlling for the impacts of age, gender, and social support. Dashed lines represent non-significant paths, and straight lines represent significant paths. ${ }^{*} p<.01,{ }^{* *} p<.001$.

The direct effects of suppression ( $B=.05, S E=.03, p>.05)$ and enhancing positive effect $(B=.01, S E=.05, p>.05)$ on psychological ill-being were non-significant, while the direct effect of cognitive reappraisal on psychological ill-being $(B=-.09, S E=.03, p<.01)$ was statistically significant. The indirect effects of suppression on psychological ill-being through autonomous behavior $(B=.05, S E=.01, p<.001)$ and self-awareness $(B=.01, S E$ $=.01, p<.01)$ were significant, while the indirect effects of suppression on psychological ill-being through relational orientation $(B=-.01, S E=.01, p>.05)$ and unbiased processing $(B=.01, S E=.01, p>.05)$ were non-significant. In the same way, self-awareness $(B=$ $-.03, S E=.01, p<.01)$ and autonomous behavior $(B=-.02, S E=.01, p<.01)$ significantly mediated the association of cognitive reappraisal with psychological ill-being, while relational orientation $(B=.00, S E=.00, p>.05)$ and unbiased processing $(B=-.00, S E=.00$, $p>.05)$ did not mediate this relationship. When it comes to enhancing positive affect, only self-awareness $(B=-.03, S E=.01, p<.01)$ emerged as the significant mediator linking it to psychological ill-being, while the indirect effects through unbiased processing $(B=.00, S E$ $=.00, p>.05)$, relational orientation $(B=.02, S E=.02, p>.05)$, and autonomous behavior 
( $B=.01, S E=.01, p>.05)$ were not significant. Table 2 summarizes the mediation types for different authenticity dimensions in linking various ER strategies to ill-being. Thirty-five percent of the variance in psychological ill-being was explained by this model.

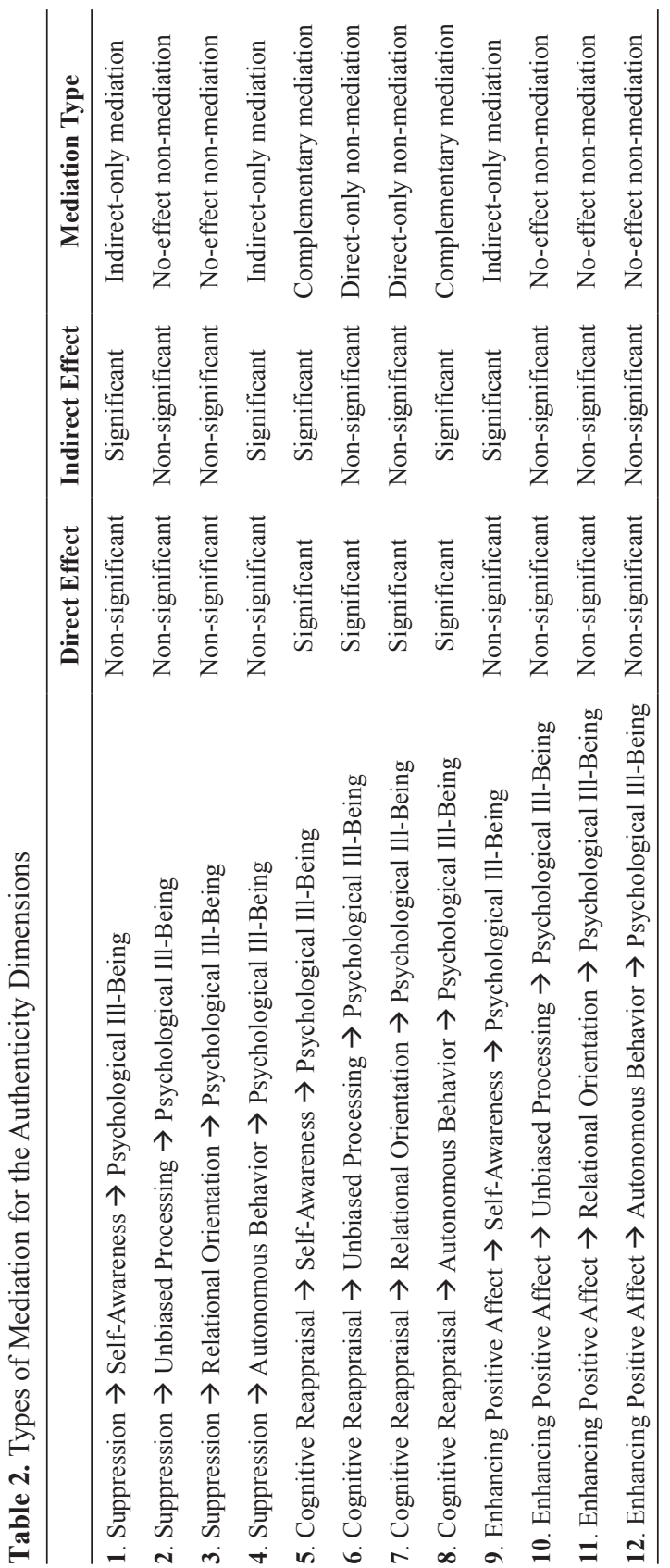




\section{DISCUSSION}

In the present study, authenticity was tested as an explaining mechanism in the ER-psychological ill-being association. Three ER strategies, which were thought to be related to authenticity, were treated as predictor variables: suppression, cognitive reappraisal, and enhancing positive affect. Authenticity was included as a mediator variable in accounting for the contributions of those ER strategies to negative psychological symptoms. The results revealed full support to the study hypotheses. Specifically, suppression intensified psychological malfunctioning by leading to a decrease in the authenticity levels $(H 1)$. On the contrary, cognitive reappraisal negatively predicted psychological ill-being by boosting authenticity (H2). Furthermore, the link between enhancing positive affect and psychological ill-being was mediated by an increase in authenticity (H3). Additional mediational analyses on the basis of various facets of authenticity showed that the self-awareness and autonomous behavior components of authenticity played a mediatory role in the association between suppression/reappraisal and psychological distress. The link between enhancing positive affect and psychological ill-being was mediated by only the self-awareness dimension of authenticity.

Previous studies also confirmed the mediatory role of general authenticity in explaining the link between suppression and well-being indicators (English \& John, 2013; Gross \& John, 2003; Impett et al., 2012). When an individual refrains from publicly expressing one's emotions, it gives rise to an inner-outer discrepancy (English \& John, 2013). The resultant inauthenticity acts as a mediator of the psychosocial implications of suppression, which is also evident in the current study. However, there might be situational or cultural exceptions to such a mediatory route. For example, in a 14-day diary study, people with a highly interdependent self-construal were protected from the psychological costs of romantic sacrifice when they were able to suppress their negative emotions during their sacrificial behaviors (Le \& Impett, 2013). Moreover, such a suppressive tendency during sacrifice fed the authenticity of highly interdependent people, which in turn led to an increase in their well-being and relationship quality. However, people with lower levels of interdependent self-construal felt inauthentic as a result of suppressive tendencies, which subsequently brought about negative psychosocial implications. As is evident, there might be certain relational contexts wherein suppression might result in positive outcomes, especially for certain types of people. 
When it comes to cognitive reappraisal, both English and John (2013), and Lenton, Slabu et al. (2013) could not find a significant correlation between reappraisal and authenticity. However, Anderson et al. (2019) demonstrated that reappraisal can contribute to authenticity if it is not perceived as a deliberate intrusion to the natural course of one's own emotional experiences. In the present study, parallel to the findings of Anderson et al. (2019), reappraisal was also found to be positively associated with authenticity, and it mediated the association between reappraisal and psychological ill-being. As explained before, the inconsistency with the earlier research might be related to the differences concerning the measurement of authenticity. Given the diversity of the assessment tools in the existing literature, it is impossible to reach firm conclusions about the link between reappraisal and authenticity. However, findings from organizational psychology can provide a reasonable ground in questioning the mediatory role of authenticity in the reappraisal and psychological health link. Deep acting, a very close associate of reappraisal, was positively related to authenticity, which in turn soothed the emotional exhaustion of the employees (Brotheridge \& Lee, 2002). Besides, Gross and John (2003) found that reappraisal was associated with both experience and expression of positive emotions. Given the importance of positive mood in the growth of authenticity (Lenton, Slabu et al., 2013), a positive affective status, which comes with reappraisal, can also explain why this ER tactic contributes to authenticity, and subsequently, to psychological health. However, reappraisal strategy might not always work for the benefit of individuals. If an individual tries to change his/her negative emotions about an issue which is central to one's identity (e.g., values, beliefs), a reduction in emotional experience can make the person feel bad about feeling better (Ford \& Troy, 2019). For example, a person who gives priority to the value of justice might get angry in the face of injustice. Reappraising such an anger-evoking event can result in immediate decreases in negative emotions. However, people are motivated not only to feel good, but also to feel the emotions which verify their intrinsic values (Tamir, 2016). Relatedly, people can feel insincere to themselves and to their values if they reappraise an identity-threatening event. The resultant feelings of inauthenticity might yield in worse psychological health (Ford \& Troy, 2019). From this point on, it might be a fruitful future attempt to investigate who might be at risk of experiencing inauthenticity in adopting reappraisal strategy.

Another finding in the present study was that authenticity mediated the relationship between enhancing positive affect and psychological ill-being. To our knowl- 
edge, such a mediatory route has never been tested before. Enhancing positive affect is an ER strategy which is used to increase existing positive emotions. Lenton, Slabu et al. (2013) showed that positive mood caused an increase in state authenticity. Moreover, when people savor through sharing their positive emotions with others, they experience a match between their inner and outer affective states. Relatedly, English and John (2013) found that expression of positive emotions was positively correlated with subjective authenticity. At the intersection of these findings, it is plausible that enhancing positive affect leads to an increase in authenticity, which in turn lessens negative psychological symptoms. However, sometimes, people make an effort to express positive emotions when they have little or no such emotions (a process known as emotion amplification). In a 10-day diary study by Le and Impett (2016), parents who amplified positive emotions during their caregiving practices reported lower levels of authenticity. Moreover, positive emotion amplification was negatively influential on certain parental outcomes (i.e., well-being, relationship quality, and responsiveness to children) via the feelings of inauthenticity. At this point, it can be stated that expression of positive emotions can threaten authenticity when it is incongruent with one's real feelings. Nonetheless, when people genuinely experience positive emotions and express them in the presence of others, such a regulatory effort can foster authenticity and thus better psychosocial outcomes. As an additional concern, Greenaway and Kalokerinos (2019) draw attention to the fact that positive emotion expression can lead to negative psychosocial outcomes if they are displayed at the wrong place. For example, in the presence of certain display rules in work settings, employees who always express their positive emotions can feel inauthentic and face with unwanted social costs (Hochschild, 1983). Therefore, retesting the currently identified mediatory route in certain work contexts (especially those which require high levels of emotional labor) can be a novel venue of research.

The present study also contributes to the existing literature in unveiling the specific aspects of authenticity which mediate the association between ER and psychological health. Most studies which were carried out with similar questions in mind treated authenticity as a single unitary process (e.g., English \& John, 2013; Lenton, Slabu et al., 2013). However, in the present study, authenticity was also examined with reference to its four different but interrelated constituents. Accordingly, the self-awareness component of authenticity mediated the link between all three ER strategies and psychological 
ill-being. The autonomous behavior component of authenticity also emerged as another mediating variable in explaining the association of both suppression and reappraisal with psychological ill-being. These findings call attention to the shielding role of successful ER through motivating people to increase self-knowledge and to behave based on their intrinsic goal strivings. Koole and Kuhl (2003) assert that rapid emotional recovery in the face of need frustration is critical to keep in touch with one's core self-system (in terms of one's self-defining memories, personal preferences, and desires). Their conceptualization of core self-system is highly similar to the awareness component in Kernis and Goldman's (2006) model of authenticity. In the light of Koole and Kuhl's (2003) theoretical considerations, successful ER can be proposed as a plausible mechanism in self-maintenance, which supplies people with authenticity in various contexts. The awareness-related paths evident in the current study can be read as an empirical confirmation of the probable link between ER and core self-accessibility. Besides, autonomous behavior component of authenticity is seen as a reflection of its self-awareness component (Kernis \& Goldman, 2006). Parallel to this, the present findings suggest that effective ER also goes hand in hand with the behavioral expression of one's genuine feelings and motives.

Neither unbiased processing nor relational orientation was a statistically significant mediator in the proposed model. In a close scrutiny of the left side of Figure 3, it is clear that all three ER strategies significantly predicted nearly all dimensions of authenticity. When the correlational patterns in Table 1 (independent of the path coefficients in the path model) were examined, it is also obvious that all four authenticity dimensions were negatively correlated to psychological ill-being. However, unbiased processing and relational orientation failed to predict psychological ill-being in the path analytic model. Such a contrast between correlational patterns and path analytic results was also evident in other authenticity-related studies. For instance, Allan, Bott and Suh (2015) investigated the mediating roles of authenticity dimensions in the relationship between mindfulness and meaning in life. Even though different elements of authenticity were positively correlated to meaning in life independent of each other, when they were put into the same model, only self-awareness and unbiased processing predicted the outcome variable. These findings suggest that some of the authenticity components lose their predictive power in explaining the outcomes of interest when the effects of other authenticity components and other study variables were simultaneously taken into account. 
When people process self-related knowledge in an unbiased manner, they do not self-aggrandize, but keep a neutral stance about both their strengths and weaknesses (Kernis \& Goldman, 2006). In this regard, the null finding concerning the link between unbiased processing and psychological health might be compatible with the previous research on positive self-illusions. People have a natural tendency to construe themselves as unrealistically positive, which in turn fosters self-esteem and better psychological adjustment (e.g., Taylor \& Stanton, 2007). On the contrary, modest (accurate) self-assessment was found to be negatively associated with subjective well-being (Elliott, 2010). In consideration of these findings, it can be stated that unbiased processing and psychological health might not show a consistent (positive) relationship in different empirical endeavors. Besides, the psychological impact of self-verification processes can explain the absence of a significant association between relational authenticity and psychological ill-being. In the case of relational authenticity, people strive to perform and validate their true selves (both positive and negative self-aspects) in their intimate relationships. However, such self-verification tendencies were related to depression and low self-esteem, especially for people with negative self-views (North \& Swann, 2009). Accordingly, relational authenticity might or might not be positively associated with psychological well-being in consideration of certain moderator variables. However, none of those potential moderators (e.g., self-esteem) were examined in the current study.

Another interesting point to be discussed in light of the present study is the discovery of different mediation types in relation to different ER strategies. While the reappraisal-related mediatory routes indicated complementary mediation, both suppression-related and savoring-related indirect effects indicated indirect-only mediation. The differentiation among those ER strategies in terms of the type of mediation might be reflecting the fact that reappraisal exemplifies an antecedent-focused regulation whereas the other two strategies exemplify response-focused regulation (Gross, 1998, 2014). After experiencing a full-blown emotion, people regulate the behavioral expression of their emotion in case of response-focused regulation. Savoring as ensuring the congruence between one's inner and outer emotional experiences, and suppression as hindering such congruence seem to have a substantial impact on authenticity. Relatedly, these two strategies seemed to confirm the currently hypothesized theoretical framework. However, in the case of the adoption of reappraisal as an antecedent-focused regulatory 
strategy, people change their cognitions in order not to experience an unwanted emotion. By reappraising an emotion-evoking situation, people disclaim the value of their original interpretation of that situation, which might disrupt their experience of authenticity. However, the present findings show that there is no one way of being authentic for the successful reappraisers. They can also internalize novel interpretations of the situations, and continue to function authentically, and thus stay protected from psychological ill-being. In addition to those indirect paths, the significance of a direct path from reappraisal to ill-being might be warning us about the likelihood of omitted mediators in explaining this direct path (Hayes \& Rockwood, 2017; Zhao et al., 2010). For example, De Castella et al. (2013) found that people who believe that emotions are fixed and uncontrollable (entity theorists) had lower levels of well-being than those who believe in the controllability and malleability of emotions (incremental theorists). Related to this finding, one possible mechanism mediating the reappraisal-mental health link might be people's implicit beliefs about emotions. Frequent usage of reappraisal strategy might convince people about the controllability of their emotions, and thus give rise to better psychological outcomes for them.

The present findings need to be interpreted in the light of several limitations as well. First, the current study used only one source of data (i.e., self-report), which might result in the social desirability effect. Measurement tools of certain ER strategies (such as reappraisal) mostly include highly desirable traits, whereas others (such as expressive suppression) include unwanted qualities (Arndt, Hoglund, \& Fujiwara, 2013). Accordingly, Arndt et al. (2013) found that reappraisal and desirable responding shared a common variance which inflated the link between the self-reported ER trait and psychopathology. The path model was tested by controlling for age, sex, and perceived social support. However, since the main research interest was about the link between ER traits and mental health, it would have been better if it had controlled the impact of social desirability as well.

Second, the cross-sectional nature of the study design precludes the cause-and-effect inferences. Prospective studies with experimental designs can aptly test whether manipulating ER strategies hinders or facilitates authenticity (as an example of such experimental attempts, see Anderson et al., 2019). The current paper both theoretically and empirically provided strong evidence for ER strategies coming before authenticity. However, it should be underlined that fit indices for the alternative model re- 
ported in the results section were not too bad. So, it is also likely that ER acts as a mediator mechanism in linking authenticity to mental health. For example, since one crucial component of authenticity is unbiased processing of self-relevant aspects, authenticity in that sense might decrease negative appraisal of one's emotional responses (Sayers, Creswell, \& Taren, 2015), and thus play a role in the reduction of suppressive tendencies and result in better psychosocial functioning. However, it is too early to decide about the causal precedency of ER over authenticity or vice versa. Related to this question, prospective longitudinal or experience-sampling studies can yield more trustworthy findings.

Third, in the current study, only three ER strategies were addressed. However, future studies can test other alternative ER strategies, such as acceptance, behavioral avoidance, mindfulness, or rumination (Naragon-Gainey, McMahon, \& Chacko, 2017) for their roles in matching people's behaviors to their true selves, and thus, contributing to their well-being.

Fourth, since the current sample was composed of exclusively undergraduate students, it is questionable to generalize these findings to other populations (e.g., older adults, psychiatric patients). People demonstrate healthier emotion regulation patterns (less frequent use of suppression, more frequent use of reappraisal) when they reach their middle ages (John \& Gross, 2004). What is more, even though the presence of a major life crisis was associated with lower levels of authenticity in each of the different life stages (early adulthood between the ages of 20-39, midlife between the ages of 4059 , and later life in the ages exceeding 60), older adults reported greater authenticity than younger adults (Robinson, Demetre, \& Litman, 2016). In relation to those finding, it is possible that the impact of ER strategies on authenticity may vary across different life stages. However, English and John (2013) showed that people are not free from the negative impact of suppression even in their later ages; the mediatory role of authenticity in the suppression-social functioning association was independent of participants' ages. Those authors addressed the interpersonal costs of regulatory failure. However, such a mediatory route might not hold true when it comes to psychological well-being of older adults. According to Urry and Gross (2010), elderly people select and optimize specific ER tactics to compensate for the losses in their internal and external resources, and they owe their well-being to such a flexibility in using different ER strategies. From this perspective, for example, it is possible that older adults might utilize suppression in 
a more adaptive fashion, as a result of which they are preserved from its negative impact. So, when it comes to older adults, not the specific type of ER strategy, but the flexibility in the usage of those strategies might bring about authenticity, and thus better psychological functioning.

Fifth, even though authenticity accompanying certain ER strategies seems to contribute to psychological health in the current study, the validity of these findings in other collectivistic contexts should always be questioned. For example, a negative association was found between authenticity and subjective well-being in the Philippines (Datu \& Reyes, 2015). However, it should be noted that the current study measured authenticity with Kernis and Goldman's (2006) multi-dimensional authenticity scale, whereas Datu and Reyes (2015) used the General Authenticity Scale of Wood, Linley, Maltby, Baliousis and Joseph (2008). According to a meta-analysis by Sutton (2020), the strongest authenticity-mental health association was detected in the usage of Kernis and Goldman's (2006) scale, whereas the weakest association was found in the usage of Wood et al.'s (2008) scale. The Turkey-Philippines difference in terms of the authenticity and mental health link might be explained with reference to the differential measurement approaches to authenticity. Yet, further cross-cultural studies are required to be sure about the nature of the relationship between authenticity and well-being.

English and John (2013) found that authenticity mediated the suppression-social functioning association independent of culture. Addressing ill-being as a dependent variable, the current study also confirmed the validity of a similar pathway in Turkey. As an additional finding in this study, authenticity played a mediatory role in explaining the impact of enhancing positive affect on ill-being. According to Miyamoto and $\mathrm{Ma}$ (2011), Western cultural scripts put an emphasis on maximizing positive emotions, whereas Eastern cultural scripts give value to a balance between positive and negative emotions. Parallel to this line of reasoning, they found that Eastern cultures discouraged individuals from using more hedonic ER strategies (e.g., savoring positive emotions more) than Western cultures did. If there is less interest in sustaining positive experiences in the collectivistic contexts, then, savoring might exert less influence on the well-being among individuals from those cultures. In a confirmation of that prediction, the direct link between enhancing positive affect and psychological distress was non-significant in the present study. However, this hedonic ER strategy was found to be negatively associated with ill-being to the extent it contributed to authenticity. Even 
though Turkey is taken as a collectivistic culture, it is located at the very middle of the individualism-collectivism continuum (Hofstede, 2001). Relatedly, whether the currently identified pathway (savoring à authenticity à ill-being) holds true even in more collectivistic cultures should be questioned in future studies.

Last but not least, the present study was also limited in its adoption of a path analytic strategy with observed variables. Both theoretical and statistical rationale for the appropriateness of calculating total scores for the current variables was provided. However, path analysis is criticized due to the fact that it assumes an error-free measurement of study variables, and this is why structural equation model (SEM) with latent variables is a superior alternative to it (Cole \& Preacher, 2014). Relatedly, prospective studies particularly with larger sample sizes could more confidently test similar hypotheses with complex SEM models.

Although ER strategies serve various functions (i.e., pain reduction, maintenance of pleasurable states, goal achievement, and personality integration; Koole, 2009), not all of those strategies are psychologically adaptive. The main purpose of the current study was to examine whether certain ER strategies were related to psychological ill-being through one potential mediating mechanism, namely, authenticity. In consideration of the present findings, it can be concluded that ER strategies can positively influence mental health to the extent that they boost authenticity.

\footnotetext{
Peer-review: Externally peer-reviewed.

Conflict of Interest: The authors have no conflict of interest to declare.

Grant Support: The authors declared that this study has received no financial support.
}

Hakem Değerlendirmesi: Dış bağımsız.

Çıkar Çatışması: Yazarlar çıkar çatışması bildirmemiştir.

Finansal Destek: Yazarlar bu çalışma için finansal destek almadığını beyan etmiştir.

\section{References/Kaynakça}

Allan, B. A., Bott, E. M., \& Suh, H. (2015). Connecting mindfulness and meaning in life: Exploring the role of authenticity. Mindfulness, 6(5), 996-1003. https://doi.org/10.1007/s12671-014-0341-z

Anderson, C. L., Chen, S., \& Ayduk, Ö. (2019). When does changing emotions harm authenticity? Distinct reappraisal strategies differentially impact subjective and observer-rated authenticity. Self and Identity. Advanced online publication. https://doi.org/10.1080/15298868.2019.1645041

Arndt, J. E., Hoglund, W. L., \& Fujiwara, E. (2013). Desirable responding mediates the relationship between emotion regulation and anxiety. Personality and Individual Differences, 55(2), 147-151. http://dx.doi.org/10.1016/j.paid.2013.02.022 
Aydoğan, D., Özbay, Y., \& Büyüköztürk, Ş. (2017). Özgünlük Ölçeği’nin uyarlanması ve özgünlük ile mutluluk arasındaki ilişkide maneviyatın aracı rolü [Adaptation of the Authentcity Scale and the mediator role of spirituality in the relationship between authenticity and happiness]. Journal of Happiness Studies, 5(1), 38-59.

Baron, R. M., \& Kenny, D. A. (1986). The moderator-mediator variable distinction in social psychological research: Conceptual, strategic, and statistical considerations. Journal of Personality and Social Psychology, 51(6), 1173-1182. https://doi.org/10.1037//0022-3514.51.6.1173

Brotheridge, C. M., \& Lee, R. T. (2002). Testing a conservation of resources model of the dynamics of emotional labor. Journal of Occupational Health Psychology, 7(1), 57-67. https://doi. org/10.1037/1076-8998.7.1.57

Brunell, A. B., Kernis, M. H., Goldman, B. M., Heppner, W., Davis, P., Cascio, E. V., \& Webster, G. D. (2010). Dispositional authenticity and romantic relationship functioning. Personality and Individual Differences, 48(8), 900-905. https://doi.org/10.1016/j.paid.2010.02.018

Bryant, F. B. (1989). A four-factor model of perceived control: Avoiding, coping, obtaining, and savoring. Journal of Personality, 57(4), 773-797. https://doi.org/10.1111/j.1467-6494.1989. tb00494.x

Byrne, B. M. (2006). Structural equation modeling with EQS: Basic concepts, applications, and programming ( $2^{\text {nd }}$ Ed.). New Jersey: Lawrence Erlbaum Associates.

Cai, W. P., Pan, Y., Zhang, S. M., Wei, C., Dong, W., \& Deng, G. H. (2017). Relationship between cognitive emotion regulation, social support, resilience and acute stress responses in Chinese soldiers: Exploring multiple mediation model. Psychiatry Research, 256, 71-78. https://doi. org/10.1016/j.psychres.2017.06.018

Cloninger, S. C. (1993). Theories of personality: Understanding persons. Englewood CliVs, NJ: Prentice Hall.

Cohen, S., Kamarck, T., \& Mermelstein, R. (1983). A global measure of perceived stress. Journal of Health and Social Behavior, 24(4), 385-396. https://doi.org/10.2307/2136404

Cole, D. A., \& Preacher, K. J. (2014). Manifest variable path analysis: Potentially serious and misleading consequences due to uncorrected measurement error. Psychological Methods, 19(2), 300-315. https://doi.org/10.1037/a0033805

Cooper, A. B., Sherman, R. A., Rauthmann, J. F., Serfass, D. G., \& Brown, N. A. (2018). Feeling good and authentic: Experienced authenticity in daily life is predicted by positive feelings and situation characteristics, not trait-state consistency. Journal of Research in Personality, 77, 57-69. https:// doi.org/10.1016/j.jrp.2018.09.005

Costa-Ramalho, S., Marques-Pinto, A., Ribeiro, M. T., \& Pereira, C. R. (2015). Savoring positive events in couple life: Impacts on relationship quality and dyadic adjustment. Family Science, 6(1), 170-180. https://doi.org/10.1080/19424620.2015.1082047

Datu, J. A. D., \& Reyes, J. A. S. (2015). The dark side of possessing power: Power reduces happiness in a collectivist context. Social Indicators Research, 124(3), 981-991. https://doi.org/10.1007/ s11205-014-0813-5

De Castella, K., Goldin, P., Jazaieri, H., Ziv, M., Dweck, C. S., \& Gross, J. J. (2013). Beliefs about emotion: Links to emotion regulation, well-being, and psychological distress. Basic and Applied Social Psychology, 35(6), 497-505. https://doi.org/10.1080/01973533.2013.840632

Deci, E. L., \& Ryan, R. M. (2000). The "what" and "why" of goal pursuits: Human needs and the self-determination of behavior. Psychological Inquiry, 11(4), 227-268. https://doi.org/10.1207/ S15327965PLI1104_01 
Eker, D., \& Arkar, H. (1995). Çok boyutlu algılanan sosyal destek ölçeğinin faktör yapısı, geçerlilik ve güvenilirliği [Factorial structure, validity, and reliability of revised form of the multidimensional scale of perceived social support]. Türk Psikoloji Dergisi, 10(34), 45-55.

Eldeleklioğlu, J., \& Eroğlu, Y. (2015). A Turkish adaptation of the emotion regulation questionnaire. Journal of Human Sciences, 12(1), 1157-1168. https://doi.org/10.14687/ijhs.v12i1.3144

Elliott, J. C. (2010). Humility: Development and analysis of a scale (Unpublished doctoral dissertation). University of Tennessee, Knoxville.

English, T., \& John, O. P. (2013). Understanding the social effects of emotion regulation: The mediating role of authenticity for individual differences in suppression. Emotion, 13(2), 314-329. https://doi. org/10.1037/a0029847

Eskin, M., Harlak, H., Demirkıran, F., \& Dereboy, Ç. (2013). Algılanan Stres Ölçeği'nin Türkçeye uyarlanması: Güvenirlik ve geçerlik analizi [The adaptation of the Perceived Stress Scale into Turkish: A reliability and validity analysis]. New Symposium Journal, 51(3), 132-140.

Field, A. (2018). Discovering statistics using IBM SPSS statistics (5 $5^{\text {th }}$ ed.). Thousand Oaks: SAGE Publications Inc.

Ford, B. Q., \& Troy, A. S. (2019). Reappraisal reconsidered: A closer look at the costs of an acclaimed emotion-regulation strategy. Current Directions in Psychological Science, 28, 195-203. https://doi. org/10.1177/0963721419827526

Fredrickson, B. L. (2001). The role of positive emotions in positive psychology: The broaden-and-build theory of positive emotions. American Psychologist, 56(3), 218-226. https://doi.org/10.1037/0003066X.56.3.218

Fredrickson, B. L. (2003). The value of positive emotions: The emerging science of positive psychology is coming to understand why it's good to feel good. American Scientist, 91(4), 330-335. https://doi. org/10.1511/2003.4.330

Garnefski, N., Kraaij, V., \& Spinhoven, P. (2001). Negative life events, cognitive emotion regulation, and emotional problems. Personality and Individual Differences, 30(8), 1311-1327. https://doi. org/10.1016/s0191-8869(00)00113-6

Gençöz, T. (2000). Pozitif ve Negatif Duygu Ölçeği: Geçerlik ve güvenirlik çalışması [Positive and Negative Affect Schedule: A study of validity and reliability]. Türk Psikoloji Dergisi, 15(46), 19-26.

Gentzler, A. L., Palmer, C. A., \& Ramsey, M. A. (2016). Savoring with intent: Investigating types of and motives for responses to positive events. Journal of Happiness Studies, 17(3), 937-958. https:// doi.org/10.1007/s10902-015-9625-9

Glidden, L. M., Billings, F. J., \& Jobe, B. M. (2006). Personality, coping style, and well-being of parents rearing children with developmental disabilities. Journal of Intellectual Disability Research, 50(12), 949-962. https://doi.org/10.1111/j.1365-2788.2006.00929.x

Goldman, B. M., \& Kernis, M. H. (2002). The role of authenticity in healthy psychological functioning and subjective well-being. Annals of the American Psychotherapy Association, 5(6), 18-20.

Grandey, A. A. (2000). Emotion regulation in the workplace: A new way to conceptualize emotional labor. Journal of Occupational Health Psychology, 5(1), 95-110. https://doi.org/10.1037//1076-8998.5.1.95

Grandey, A. A., Fisk, G. M., Mattila, A. S., Jansen, K. J., \& Sideman, L. A. (2005). Is "service with a smile" enough? Authenticity of positive displays during service encounters. Organizational Behavior and Human Decision Processes, 96(1), 38-55. https://doi.org/10.1016/j.obhdp.2004.08.002

Greenaway, K. H., \& Kalokerinos, E. K. (2017). Suppress for success? Exploring the contexts in which expressing positive emotion can have social costs. European Review of Social Psychology, 28(1), 134-174. https://doi.org/10.1080/10463283.2017.1331874 
Greenaway, K. H., \& Kalokerinos, E. K. (2019). The intersection of goals to experience and express emotion. Emotion Review, 11(1), 50-62. https://doi.org/10.1177/1754073918765665

Gross, J. J. (1998). The emerging field of emotion regulation: An integrative review. Review of General Psychology, 2(3), 271-299. https://doi.org/10.1037/1089-2680.2.3.271

Gross, J. J. (2014). Emotion regulation: Conceptual and empirical foundations. In J. J. Gross (Ed.), Handbook of emotion regulation ( $2^{\text {nd }}$ ed., pp. 3-20). New York, NY: Guilford.

Gross, J. J. (2015). Emotion regulation: Current status and future prospects. Psychological Inquiry, 26(1), 1-26. https://doi.org/10.1080/1047840X.2014.940781

Gross, J. J., \& John, O. P. (2003). Individual differences in two emotion regulation processes: Implications for affect, relationships, and well-being. Journal of Personality and Social Psychology, 85(2), 348-362. https://doi.org/10.1037/0022-3514.85.2.348

Haga, M. H., Kraft, P., \& Corby, E. (2009). Emotion regulation: Antecedents and well-being outcomes of cognitive reappraisal and expressive suppression in cross-cultural samples. Journal of Happiness Studies, 10(3), 271-291. https://doi.org/10.1007/s10902-007-9080-3

Hayes, A. F., \& Rockwood, N. J. (2017). Regression-based statistical mediation and moderation analysis in clinical research: Observations, recommendations, and implementation. Behaviour Research and Therapy, 98, 39-57. https://doi.org/10.1016/j.brat.2016.11.001

Hochschild, A. R. (1983). The managed heart: Commercialization of human feeling. Berkeley, CA: University of California Press.

Hofmann, S. G., Carpenter, J. K., \& Joshua, C. (2016). Interpersonal emotion regulation questionnaire (IERQ): Scale development and psychometric characteristics. Cognitive Therapy and Research, 40(3), 341-356. https://doi.org/10.1007/s10608-016-9756-2

Hofstede, G. (2001). Culture's consequences: Comparing values, behaviors, institutions, and organizations (2. Ed.). Thousand Oaks, CA: Sage.

Hu, L. T., \& Bentler, P. M. (1999). Cutoff criteria for fit indexes in covariance structure analysis: Conventional criteria versus new alternatives. Structural Equation Modeling: A Multidisciplinary Journal, 6(1), 1-55. https://doi.org/10.1080/10705519909540118

Impett, E. A., Kogan, A., English, T., John, O., Oveis, C., Gordon, A. M., \& Keltner, D. (2012). Suppression sours sacrifice: Emotional and relational costs of suppressing emotions in romantic relationships. Personality and Social Psychology Bulletin, 38(6), 707-720. https://doi. org/10.1177/0146167212437249

İmamoğlu,E.O.(1998). Individualism and collectivisminamodel and scale of balanced differentiation and integration. Journal of Psychology, 132(1), 95-105. https://doi.org/10.1080/00223989809599268

İmamoğlu, E. O., \& Beydoğan, B. (2011). Impact of self orientations and work-context-related variables on the well-being of public- and private-sector Turkish employees. The Journal of Psychology: Interdisciplinary and Applied, 145(4), 267-296. https://doi.org/10.1080/00223980.2011.563328

İmamoğlu, E. O., Günaydın, G., \& Selçuk, E. (2011). Özgün benliğin yordayıcıları olarak kendileşme ve ilişkililik: Cinsiyetin ve kültürel yönelimlerin ötesinde [Individuation and relatedness as predictors of the authentic self: Beyond gender and cultural orientations]. Türk Psikoloji Dergisi, 26(67), 27-43.

John, O. O., \& Gross, J. J. (2004). Healthy and unhealthy emotion regulation: Personality processes, individual differences, and life span development. Journal of Personality, 72(6), 1301-1334. https://doi.org/10.1111/j.1467-6494.2004.00298.x

Jose, P. E., Lim, B. T., \& Bryant, F. B. (2012). Does savoring increase happiness? A daily diary study. The Journal of Positive Psychology, 7(3), 176-187. https://doi.org/10.1080/17439760.2012.671345 
Kernis, M. H., \& Goldman, B. M. (2006). A multicomponent conceptualization of authenticity: Theory and research. Advances in Experimental Social Psychology, 38, 283-357. https://doi.org/10.1016/ S0065-2601(06)38006-9

Keyes, C. L. M. (2005). Mental illness and/or mental health? Investigating axioms of the complete state model of health. Journal of Consulting and Clinical Psychology, 73(3), 539-548. https://doi. org/10.1037/0022-006X.73.3.539

Kifer, Y., Heller, D., Perunovic, W. Q., \& Galinsky, A. D. (2013). The good life of the powerful: The experience of power and authenticity enhances subjective well-being. Psychological Science, 24(3), 280-288. https://doi.org/10.1177/0956797612450891

Kim, J., Chen, K., Davis, W. E., Hicks, J. A., \& Schlegel, R. J. (2019). Approaching the true self: Promotion focus predicts the experience of authenticity. Journal of Research in Personality, 78, 165-176. https://doi.org/10.1016/j.jrp.2018.12.001

Kirwan, M., Svenson, D. W., Pickett, S. M., \& Parkhill, M. R. (2019). Emotion regulation as a mediator between sleep quality and interpersonal aggression. Personality and Individual Differences, 148, 32-37. https://doi.org/10.1016/j.paid.2019.05.018

Kitayama, S., Markus,H. R., \& Kurokawa, M. (2000). Culture, emotion, and well-being: Good feelings in Japan and the United States. Cognition and Emotion, 14(1), 93-124. https://doi.org/10.1080/026999300379003

Koole, S. L. (2009). The psychology of emotion regulation: An integrative review. Cognition \& Emotion, 23(1), 4-41. https://doi.org/10.1080/02699930802619031

Koole, S. L., \& Kuhl, J. (2003). In the search of the real self: A functional perspective on optimal selfesteem and authenticity. Psychological Inquiry, 14(1), 1-16.

Kraus, M. W., Chen, S., \& Keltner, D. (2011). The power to be me: Power elevates self-concept consistency and authenticity. Journal of Experimental Social Psychology, 47(5), 974-980. https:// doi.org/10.1016/j.jesp.2011.03.017

Kuyumcu, B., \& Kabasakaloğlu, A. (2018). Otantik olmanın duyuşsal iyi oluşu (pozitif-negatif duygu durumu) yordama gücü: Türk ve İngiliz üniversite öğrencileri arasında otantik olma ve pozitifnegatif duygu durumu [The predictive power of authenticity on emotional well-being (PositiveNegative Affect): Authenticity and positive-negative affect among Turkish and English university students]. Yüksekögrretim ve Bilim Dergisi, 8(1), 184-193. https://doi.org/10.5961/jhes.2018.260

La Guardia, J. G., Ryan, R. M., Couchman, C. E., \& Deci, E. L. (2000). Within-person variation in security of attachment: A self-determination theory perspective on attachment, need fulfillment, and wellbeing. Journal of Personality and Social Psychology, 79(3), 367-384. https://doi.org/10.1037/00223514.79.3.367

Lakey, C. E., Kernis, M. H., Heppner, W. L., \& Lance, C. E. (2007). Individual differences in authenticity and mindfulness as predictors of verbal defensiveness. Journal of Research in Personality, 42(1), 30-38. https://doi.org/10.1016/j.jrp.2007.05.002

Le, B. M., \& Impett, E. A. (2013). When holding back helps: Suppressing negative emotions during sacrifice feels authentic and is beneficial for highly interdependent people. Psychological Science, 24(9), 1809-1815. https://doi.org/10.1177/0956797613475365

Le, B. M., \& Impett, E. A. (2016). The costs of suppressing negative emotions and amplifying positive emotions during parental caregiving. Personality and Social Psychology Bulletin, 42(3), 323-336. https://doi.org/10.1177/0146167216629122

Lenton, A. P., Bruder, M., Slabu, L., \& Sedikides, C. (2013). How does "being real" feel? The experience of state authenticity. Journal of Personality, 81(3), 276-289. https://doi.org/10.1111/ j.1467-6494.2012.00805.x 
Lenton, A. P., Slabu, L., Sedikides, C., \& Power, K. (2013). I feel good, therefore I am real: Testing the causal influence of mood on state authenticity. Cognition \& Emotion, 27(7), 1202-1224. https://doi. org/10.1080/02699931.2013.778818

Livingstone, K. M., \& Srivastava, S. (2012). Up-regulating positive emotions in everyday life: Strategies, individual differences, and associations with positive emotion and well-being. Journal of Research in Personality, 46(5), 504-516. https://doi.org/10.1016/j.jrp.2012.05.009

Matsumoto, D. (1990). Cultural similarities and differences in display rules. Motivation and Emotion, 14(3), 195-214. https://doi.org/10.1007/BF00995569

Mazzuca, S., Kafetsios, K., Livi, S., \& Presaghi, F. (2018). Emotion regulation and satisfaction in long-term marital relationships: The role of emotional contagion. Journal of Social and Personal Relationships, 1-16. https://doi.org/10.1177/0265407518804452

Miyamoto, Y., \& Ma, X. (2011). Dampening or savoring positive emotions: A dialectical cultural script guides emotion regulation. Emotion, 11(6), 1346-1357. https://doi.org/10.1037/a0025135

Naragon-Gainey, K., McMahon, T. P., \& Chacko, T. P. (2017). The structure of common emotion regulation strategies: A meta-analytic examination. Psychological Bulletin, 143(4), 384-427. https:// doi.org/10.1037/bul0000093

Niedenthal, P. M., \& Ric, F. (2017). Psychology of emotion ( $2^{\text {nd }}$ ed.). New York, NY: Routledge.

North, R. J., \& Swann, W. B. (2009). Self-verification 360: Illuminating the light and dark sides. Self and Identity, 8(2-3), 131-146. https://doi.org/10.1080/15298860802501516

Peng, K., \& Nisbett, R. E. (1999). Culture, dialectics, and reasoning about contradiction. American Psychologist, 54(9), 741-754. https://doi.org/10.1037/0003-066X.54.9.741

Pepping, C. A., Duvenage, M., Cronin, T. J., \& Lyons, A. (2016). Adolescent mindfulness and psychopathology: The role of emotion regulation. Personality and Individual Differences, 99, 302307. https://doi.org/10.1016/j.paid.2016.04.089

Quoidbach, J., Berry, E. V., Hansenne, M., \& Mikolajczak, M. (2010). Positive emotion regulation and well-being: Comparing the impact of eight savoring and dampening strategies. Personality and Individual Differences, 49(5), 368-373. https://doi.org/10.1016/j.paid.2010.03.048

Radloff, L. S. (1977). The CES-D scale: A self-report depression scale for research in the general population. Applied Psychological Measurement, 1(3), 385-401. https://doi.org/10.1177/014662167700100306

Reis, H. T., Sheldon, K. M., Gable, S. L., Roscoe, J., \& Ryan, R. M. (2000). Daily well-being: The role of autonomy, competence, and relatedness. Personality and Social Psychology Bulletin, 26(4), 419-435. https://doi.org/10.1177/0146167200266002

Robinson, O. C., Demetre, J. D., \& Litman, J. A. (2016). Adult life stage and crisis as predictors of curiosity and authenticity: Testing inferences from Erikson's lifespan theory. International Journal of Behavioral Development, 41(3), 426-431. https://doi.org/10.1177/0165025416645201

Rogers, C. (1961). On becoming a person: A therapist's view of psychotherapy. Boston, MA: Houghton Mifflin.

Ryan, R. M., LaGuardia, J. G., \& Rawsthorne, L. J. (2005). Self-complexity and the authenticity of self-aspects: Effects on well-being and resilience to stressful events. North American Journal of Psychology, 7(3), 431-448.

Samios, C., \& Khatri, V. (2019). When times get tough: Savoring and relationship satisfaction in couples coping with a stressful life event. Anxiety, Stress, \& Coping, 32(2), 125-140. https://doi.or $\mathrm{g} / 10.1080 / 10615806.2019 .1570804$

Sayers, W. M., Creswell, J. D., \& Taren, A. (2015). The emerging neurobiology of mindfulness and emotion processing. In B. D. Ostafin, M. D. Robinson, \& B. P. Meier (Eds.), Handbook of mindfulness and self-regulation (pp. 9-22). Springer Science + Business Media. 
Shevlin, M., \& Miles, J. N. (1998). Effects of sample size, model specification, and factor loadings on the GFI in confirmatory factor analysis. Personality and Individual Differences, 25(1), 85-90. https://doi.org/10.1016/S0191-8869(98)00055-5

Sutton, A. (2020). Living the good life: A meta-analysis of authenticity, well-being and engagement. Personality and Individual Differences, 513, 109645. https://doi.org/10.1016/j.paid.2019.109645

Sümer, N., Helvaci, E., \& Misirlisoy, M. (2013). Employability of psychology graduates and their job satisfaction in Turkey: An online survey. Psychology Learning \& Teaching, 12(2), 189-195. https:// doi.org/10.2304/plat.2013.12.2.189

Tamir, M. (2016). Why do people regulate their emotions? A taxonomy of motives in emotion regulation. Personality and Social Psychology Review, 20(3), 199-222. https://doi. org $/ 10.1177 / 1088868315586325$

Tatar, A., \& Saltukoğlu, G. (2010). The adaptation of the CES-depression scale into Turkish through the use of confirmatory factor analysis and item response theory and the examination of psychometric characteristics. Bulletin of Clinical Psychopharmacology, 20(3), 213-227.

Taylor, S. E., \& Stanton, A. L. (2007). Coping resources, coping processes, and mental health. Annual Review of Clinical Psychology, 3, 377-401. https://doi.org/10.1146/annurev. clinpsy.3.022806.091520

Tugade, M. M., \& Fredrickson, B. L. (2007). Regulation of positive emotions: Emotion regulation strategies that promote resilience. Journal of Happiness Studies, 8, 311-333. https://doi. org/10.1007/s10902-006-9015-4

Urry, H. L., \& Gross, J. J. (2010). Emotion regulation in older age. Current Directions in Psychological Science, 19(6), 352-357. https://doi.org/10.1177/0963721410388395

Watson, D., Clark, L. A., \& Tellegen, A. (1988). Development and validation of brief measures of positive and negative affect: The PANAS scales. Journal of Personality and Social Psychology, 54(6), 1063-1070. https://doi.org/10.1037/0022-3514.54.6.1063

Westerhof, G. J., \& Keyes, C. L. M. (2010). Mental illness and mental health: The two continua model across the lifespan. Journal of Adult Development, 17(2), 110-119. https://doi.org/10.1007/s10804009-9082-y

Wickham, R. E., Williamson, R. E., Beard, C. L., Kobayashi, C. L. B., \& Hirst, T. W. (2016). Authenticity attenuates the negative effects of interpersonal conflict on daily well-being. Journal of Research in Personality, 60, 56-62. https://doi.org/10.1016/j.jrp.2015.11.006

Wood, A. M. L., Linley, P. A., Maltby, J., Baliousis, M., \& Joseph, S. (2008). The authentic personality: A theoretical and empirical conceptualization and the development of the authenticity scale. Journal of Counseling Psychology, 55(3), 385-399. https://doi.org/10.1037/0022-0167.55.3.385

Yücel, E., İnan, E., Süsen, Y., Karanfil, D., \& Yalçınkaya-Alkar, Ö. (2017, July). For better or worse: An exploration about the nature of interpersonal emotion regulation. Paper presented at 15 th European Congress of Psychology (ECP). Amsterdam, Netherlands.

Zhao, X., Lynch, J. G., Jr., \& Chen, Q. (2010). Reconsidering Baron and Kenny: Myths and truths about mediation analysis. Journal of Consumer Research, 37(2), 197-206. https://doi.org/10.1086/651257

Zimet, G. D., Dahlem, N. W., Zimet, S. G., \& Farley, G. K. (1988). The multidimensional scale of perceived social support. Journal of Personality Assessment, 52(1), 30-41. https://doi.org/10.1207/ s15327752jpa5201_2 